\title{
New Insights Into the Role of Seed Oil Body Proteins in Metabolism and Plant Development
}

\author{
Qun Shao, Xiaofan Liu, Tong Su, Changle Ma* and Pingping Wang* \\ Shandong Provincial Key Laboratory of Plant Stress, College of Life Sciences, Shandong Normal University, Jinan, China
}

Oil bodies (OBs) are ubiquitous dynamic organelles found in plant seeds. They have attracted increasing attention recently because of their important roles in plant physiology. First, the neutral lipids stored within these organelles serve as an initial, essential source of energy and carbon for seed germination and post-germinative growth of the seedlings. Secondly, they are involved in many other cellular processes such as stress responses, lipid metabolism, organ development, and hormone signaling. The biological functions

OPEN ACCESS

Edited by:

Xue-Rong Zhou,

Commonwealth Scientific and Industrial Research Organisation, Australia

Reviewed by:

Ray J. Rose,

University of Newcastle, Australia

Jay Shockey,

United States Department of Agriculture, United States

${ }^{*}$ Correspondence: Changle Ma

machangle@sdnu.edu.cn

Pingping Wang

pingping.wang@sdnu.edu.cn

Specialty section: This article was submitted to

Plant Metabolism and Chemodiversity,

a section of the journal

Frontiers in Plant Science

Received: 25 September 2019 Accepted: 08 November 2019 Published: 10 December 2019

Citation:

Shao Q, Liu X, Su T, Ma C and Wang $P$ (2019) New Insights Into the

Role of Seed Oil Body Proteins in Metabolism and Plant Development.

Front. Plant Sci. 10:1568.

doi: 10.3389/fp/s.2019.01568 of seed OBs are dependent on structural proteins, principally oleosins, caleosins, and steroleosins, which are embedded in the OB phospholipid monolayer. Oleosin and caleosin proteins are specific to plants and mainly act as OB structural proteins and are important for the biogenesis, stability, and dynamics of the organelle; whereas steroleosin proteins are also present in mammals and play an important role in steroid hormone metabolism and signaling. Significant progress using new genetic, biochemical, and imaging technologies has uncovered the roles of these proteins. Here, we review recent work on the structural or metabolic roles of these proteins in OB biogenesis, stabilization and degradation, lipid homeostasis and mobilization, hormone signal transduction, stress defenses, and various aspects of plant growth and development.

Keywords: oil body intrinsic proteins, lipid metabolism, hormone signaling, stress responses, plant development

\section{INTRODUCTION}

Lipids are essential for all kingdoms of life because they are involved in a remarkably wide variety of cellular functions, including energy homeostasis, membrane remodeling, and cell signaling (Pyc et al., 2017). The cellular mechanisms of assembling, storing, and supplying lipids by forming intracellular lipid particles are relatively conserved in all eukaryotes, including yeast (Leber et al., 1994), insects (Zhang et al., 2010), mammals (Murphy, 2001), and plants (Bao et al., 2018), as well as prokaryotes (Wältermann et al., 2005); Traditionally, these lipid particles have had a variety of names, including oil bodies (OB), oleosomes, spherosomes, lipid bodies, lipid droplets (LD), or lipid vesicles. In recent years, the terms $\mathrm{OB}$ or $\mathrm{LD}$ have been adopted by most laboratories. OBs are present in seeds, leaves, pollens, fruits, flowers, and roots of higher plants (angiosperms), the vegetative and reproductive organs of lower plants, the glands and adipose tissues of mammals, as well as in algae, fungi, nematodes, and bacteria (Huang, 2013; Shimada et al., 2018).

These organelles consist of a densely packed hydrophobic core of neutral lipids surrounded by a phospholipid monolayer decorated by three main classes of OB-associated proteins: oleosins, caleosins, and steroleosins. The acyl moieties of the phospholipid molecules face inward with the hydrophobic triacylglycerol (TAG) in the matrix and the hydrophilic phospholipid head groups 
in the cytosol (Tzen et al., 1997). OBs in the seeds of plants are generally circular to ovoid with the average diameter of $0.5-2.5$ $\mu \mathrm{m}$, but the diameter of some OBs can be 2-3 times larger than $2.5 \mu \mathrm{m}$, such as in legume seeds (Tzen et al., 1993; Song et al., 2017). Recently, 3D reconstruction analysis showed that the volume of most OBs in Brassica napus seeds were less than 100 $\mu \mathrm{m}^{3}$ (Yin et al., 2018).

OBs are highly dynamic organelles and are actively involved in many diverse physiological processes including membrane biogenesis supporting organelle or cell growth, diurnal regulation process, hormone signaling, and plant growth and development. OBs also act as a "sink" for toxic fatty acids which can be lethal to the cells (Pyc et al., 2017). The decomposition of OBs by proteases and lipases and the subsequent $\beta$-oxidation of the released fatty acids can provide carbon and energy during seed germination and post-germinative growth of the seedlings (Huang, 1996). As a result of their importance in plant physiology, seed OBs have been intensively studied in the past few decades, surpassing our knowledge in nonplant organisms.

The functions of OBs are dependent on three classes of $\mathrm{OB}$ intrinsic proteins: oleosins, caleosins, and steroleosins. These distinct structural $\mathrm{OB}$ proteins are associated with specific biological functions. The structural or metabolic roles of these proteins in the control of lipid store mobilization, OB degradation, hormone signal transduction, and stress defenses are discussed in this review.

\section{OB INTRINSIC PROTEINS}

\section{Oleosin, Caleosin, and Steroleosin}

OBs in the intact cells of a mature seed never coalesce or aggregate, even after long-term storage, because the entire surface of an $\mathrm{OB}$ is covered by proteins (Leprince et al., 1998). The most abundant protein constituents are the structural alkaline proteins termed oleosins. Oleosins are also located in other tissues such as the tapetum and the external surface of pollen grains (Kim et al., 2002). They have a molecular mass of $15-50 \mathrm{kDa}$, depending on the isoform and plant species in which they occur (Tzen et al., 1990; Jolivet et al., 2009).

The oleosin gene was first cloned from maize (Vance and Huang, 1987). In Arabidopsis, 16 oleosin proteins have been identified, including five seed-type oleosins, eight anther-type oleosins, and three seed-and-anther type oleosins (Table 1). The most abundant oleosin in Arabidopsis seeds is oleosin-1 (OLE1), followed by oleosin-2 (OLE1) (D’Andrea, 2016; Shimada et al., 2008). Seed-type oleosins are involved in regulating both OB size and seed germination. Anther-type oleosins have glycinerich domains not found in seed-type oleosins and function in stabilizing pollen OBs and forming pollen and the pollen coat (Mayfield et al., 2001; Kim et al., 2002).

Another major group of $\mathrm{OB}$ structural proteins are the caleosins. Caleosin was first reported (named as Sopl) as a minor constituent in purified OBs from sesame (Sesamum indicum) seeds. Their name arose from their ability to bind calcium and their oleosin-like structures (Chen et al., 1998; 1999). Eight caleosin genes (AtCLO1-AtCLO8) have been found in the
Arabidopsis genome (Table 1) (Hanano et al., 2006; Shen et al., 2014). Among them, AtCLO1 and AtCLO2 are preferentially expressed in developing embryos and seeds during seed maturation and the first days following germination. AtCLO5 expression level is low but detectable in buds. AtCLO3 is mainly expressed in above-ground tissues, whereas ATCLO4 is expressed in the vascular bundles in all major plant tissues, as well as in guard cells and germinating seeds (Aubert et al., 2010; Kim et al., 2011; Shen et al., 2014). Expression data for the other caleosin genes are still scarce.

In contrast with oleosins, caleosins are present in more primitive species, such as fungi and single-celled algae (Charuchinda et al., 2015), whereas oleosins are only present in more recent higher plant species (Huang et al., 2009). Because of these observations, oleosin may have been derived from caleosin, which may represent a more ancient structural $\mathrm{OB}$ protein in plants, and has become more specifically associated with $\mathrm{OB}$ formation and maintenance (Jiang and Tzen, 2010).

The earliest identified plant steroleosins were Sop2 and Sop3 from sesame, named steroleosin-A and -B, respectively. They are homologous proteins with sterol-binding and sterol-coupling dehydrogenase activity (Chen et al., 1998; Lin et al., 2002). Later, the homologous steroleosin encoded by At5g50600 was purified from Arabidopsis seed OBs (Jolivet et al., 2004). This protein, with a high degree of similarity to Sop2, exhibits hydroxysteroid dehydrogenase (HSD) activity and belongs to the short-chain steroid dehydrogenase reductase superfamily (SDR) which is involved in sterol-regulated signal transduction in diverse organisms. As a result, this protein is named AtHSD1 (d'Andréa et al., 2007). There are eight putative steroleosin homologs in the Arabidopsis genome, including two identical copies of AtHSD1, two identical copies of AtHSD4, and four other homologs. Sequence alignment showed that the promoter, coding sequence, and terminator of two copies of the AtHSD1 gene, and two copies of the AtHSD4 gene are completely identical at the nucleotide level (Table 1) (Li et al., 2007).

Unlike oleosin and caleosin proteins which are specific to plants, OB-associated sterol dehydrogenases are also present in mammals. However, phylogenic analysis indicates that plant $17 \beta$-HSDs display only $24 \%$ identity with those corresponding sequences in mammals. These enzymes have been demonstrated to be important in steroid hormone metabolism and signaling in both plants and mammals (d'Andréa et al., 2007).

\section{Structure of OB-Associated Proteins}

All oleosins and caleosins have three regions: a hydrophilic $\mathrm{N}$-terminal domain, a specific and highly conserved hydrophobic central domain and a hydrophilic C-terminal $\alpha$-helical domain (Tzen and Huang, 1992). The central domain forms a hairpinlike structure composed of antiparallel $\beta$ strands connected by a proline knot motif and is responsible for $\mathrm{OB}$ localization. The $\mathrm{N}$ - and C-terminals are exposed to the cytoplasm, and the central domain anchors the protein in the OB membrane (Huang, 1996; Huang and Huang, 2017). In contrast to oleosin, caleosin has a significantly larger $\mathrm{N}$-terminal hydrophilic domain containing an EF-hand calcium binding motif and several potential 
TABLE 1 | Three OB-associated proteins in Arabidopsis thaliana

\begin{tabular}{|c|c|c|c|}
\hline TAIR locus & Description & Putative function & Reference \\
\hline \multicolumn{4}{|l|}{ Oleosin } \\
\hline AT4G25140 & OLE1, OLEO1, OLEOSIN 1 & $\begin{array}{l}\text { Major seed OB protein, involved in seed lipid accumulation } \\
\text { and freezing tolerance of seeds. }\end{array}$ & van Rooijen et al., 1992; Siloto et al, 2006 \\
\hline AT5G40420 & OLE2, OLEO2, OLEOSIN 2 & $\begin{array}{l}\text { Major seed OB protein, involved in seed lipid accumulation } \\
\text { and freezing tolerance of seeds. }\end{array}$ & Zou et al.,1995; Shimada et al,2008 \\
\hline AT3G27660 & OLEO3, OLEOSIN3 & $\begin{array}{l}\text { Seed OB protein, involved in seed lipid accumulation and } \\
\text { OB degradation. }\end{array}$ & Kirik et al., 1996; Deruyffelaere et al., 2015 \\
\hline AT3G01570 & Oleosin 4, OLE4 & $\begin{array}{l}\text { Major seed OB protein, involved in seed lipid accumulation } \\
\text { and freezing tolerance of seeds. }\end{array}$ & Kim et al., 2002; Shimada et al, 2008 \\
\hline AT5G51210 & Oleosin 5, OLE5 & $\begin{array}{l}\text { Minor seed OB oleosin, a possible role for these oleosins in } \\
\text { the control of OB dynamics. }\end{array}$ & Kirik et al., 1996; Deruyffelaere et al., 2015 \\
\hline AT5G07510 & ATGRP14, glycine rich protein 14 & A pollen coat protein. No report of function. & Mayfield and Preuss, 2000 \\
\hline AT5G07540 & ATGRP17, glycine rich protein 17 & A pollen coat protein. No report of function. & de Oliveira et al., 1993 \\
\hline AT5G07530 & ATGRP17, glycine rich protein 17 & $\begin{array}{l}\text { A glycine rich protein containing oleosin domain, found on } \\
\text { mature pollen coat, have a role in initiating pollination. }\end{array}$ & Mayfield and Preuss, 2000 \\
\hline AT5G07520 & ATGRP18, glycine rich protein 18 & A pollen coat protein. No report of function. & de Oliveira et al., 1993 \\
\hline AT5G07550 & ATGRP19, glycine rich protein 19 & A glycine rich pollen coat protein. No report of function. & de Oliveira et al., 1993 \\
\hline AT5G07560 & ATGRP20, glycine rich protein 20 & $\begin{array}{l}\text { A glycine rich protein expressed specifically in the florets. No } \\
\text { report of function. }\end{array}$ & Mayfield et al., 2001 \\
\hline AT3G18570 & Oleosin family protein & $\begin{array}{l}\text { A protein expressed in both maturing seeds and florets. No } \\
\text { report of function. }\end{array}$ & Kim et al., 2002 \\
\hline AT2G25890 & Oleosin family protein & $\begin{array}{l}\text { A protein expressed in both maturing seeds and florets. No } \\
\text { report of function. }\end{array}$ & Kim et al., 2002 \\
\hline AT1G48990 & Oleosin family protein & $\begin{array}{l}\text { A protein expressed in both maturing seeds and florets. No } \\
\text { report of function. }\end{array}$ & Kim et al., 2002 \\
\hline AT5G07600 & Oleosin family protein & $\begin{array}{l}\text { A oleosin expressed specifically in the florets (tapetum). No } \\
\text { report of function. }\end{array}$ & Kim et al., 2002 \\
\hline AT5G61610 & Oleosin family protein & $\begin{array}{l}\text { A oleosin expressed specifically in the florets (tapetum). No } \\
\text { report of function. }\end{array}$ & Kim et al., 2002 \\
\hline \multicolumn{4}{|c|}{ P } \\
\hline AT4G26740 & AtCLO1, ATPXG1, ATS1, CLO1 & $\begin{array}{l}\text { A caleosin in seed OBs. Catalyze hydroperoxide-dependent } \\
\text { mono-oxygenation reactions and sensitive to some } \\
\text { hormones. }\end{array}$ & Naested et al., 2000; Hanano et al., 2006 \\
\hline AT5G55240 & AtCLO2, ATS2, ATPXG2 & $\begin{array}{l}\text { A seed caleosin with peroxygenase activity has roles in } \\
\text { dormancy or germination of seeds. }\end{array}$ & Hanano et al., 2006 \\
\hline AT2G33380 & AtCLO3, ATPXG3, RD20 & $\begin{array}{l}\text { A caleosin expressed in various organs acts as a } \\
\text { peroxygenase involved in oxylipin metabolism during stress } \\
\text { and sensitive to various stresses. }\end{array}$ & Aubert et al., 2010; Blée et al., 2014 \\
\hline AT1G70670 & AtCLO4, ATPXG4 & $\begin{array}{l}\text { A stress-responsive and caleosin-like protein mainly } \\
\text { expressed in leaf and was sensitive to some stresses in root } \\
\text { and cell culture. }\end{array}$ & $\begin{array}{l}\text { Hanano et al., 2006; Kim et al., 2011; Blée } \\
\text { et al., } 2012\end{array}$ \\
\hline AT1G23240 & AtCLO5, ATPXG5 & A caleosin was mainly expressed in bud. & Hanano et al., 2006 \\
\hline AT1G70680 & AtCLO6 & Caleosin family protein. No report of function. & Shen et al., 2014 \\
\hline AT1G23250 & AtCLO7 & $\begin{array}{l}\text { Be without conserved EF-hand and might lost the ability to } \\
\text { bind calcium }\end{array}$ & Shen et al., 2014 \\
\hline AT5G29560 & AtCLO8 & No report & Shen et al., 2014 \\
\hline \multicolumn{4}{|l|}{ Steroleosin } \\
\hline $\begin{array}{l}\text { AT5G50600 / } \\
\text { AT5G50700 }\end{array}$ & AtHSD1 & $\begin{array}{l}\text { A hydroxysteroid dehydrogenase in seed OBs acts } \\
\text { as a NADP }{ }^{+} \text {-dependent } 11 \beta-, 17 \beta \text {-hydroxysteroid } \\
\text { dehydrogenase/17 } \beta \text {-ketosteroid reductase. }\end{array}$ & Jolivet et al., 2004; d’Andréa et al., 2007 \\
\hline AT3G47350 & AtHSD2 & A putative hydroxysteroid dehydrogenase (HSD) & Li et al., 2007 \\
\hline AT3G47360 & AtHSD3 & A putative hydroxysteroid dehydrogenase (HSD). & Li et al., 2007 \\
\hline $\begin{array}{l}\text { AT5G50590/ } \\
\text { AT5G50690 }\end{array}$ & AtHSD4 & A putative hydroxysteroid dehydrogenase (HSD). & Li et al., 2007; Baud et al., 2009 \\
\hline AT4G10020 & AtHSD5 & A putative hydroxysteroid dehydrogenase (HSD). & Li et al., 2007 \\
\hline AT5G50770 & AtHSD6 & A putative hydroxysteroid dehydrogenase (HSD). & Li et al., 2007 \\
\hline
\end{tabular}

phosphorylation sites within the C-terminal hydrophilic domain. Both the $\mathrm{N}$ - and $\mathrm{C}$-terminal regions of caleosin also contain heme-binding sites with conserved histidine residues that together coordinate the binding of heme prosthetic groups (Figure 1) (Hanano et al., 2006; Chapman et al., 2012).
Unlike oleosin and caleosin, steroleosin possesses a distinctive structure containing an $\mathrm{N}$-terminal hydrophobic OB-anchoring segment and a soluble sterol-binding dehydrogenase/reductase domain, located in the cytosol. A unique proline knob motif is in the middle of the steroleosin $\mathrm{N}$-terminus, corresponding 
A

\section{oleosin}

cytosol

PL

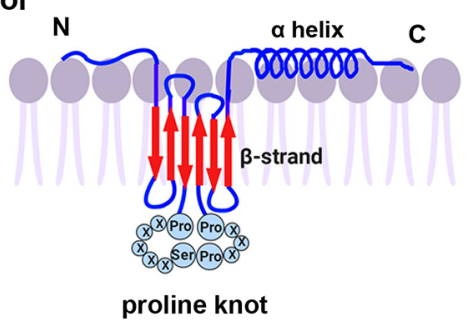

B

\section{caleosin}

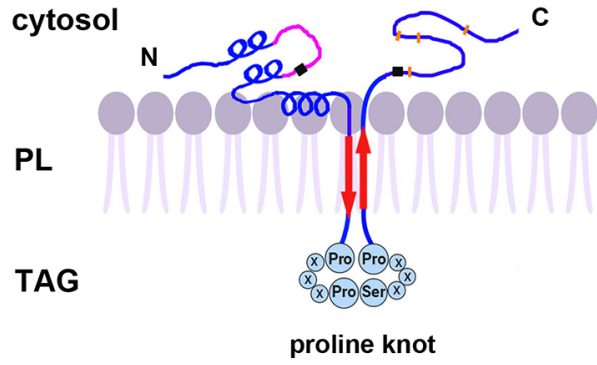

C

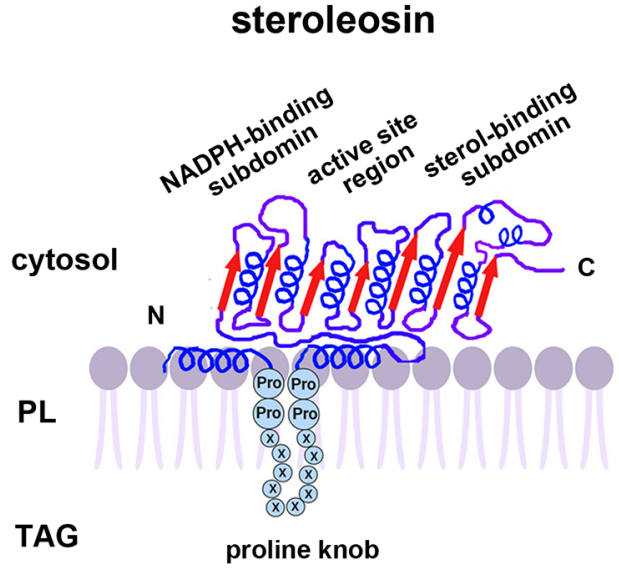

J $\mathrm{Ca}^{2+}$ binding motif

phosphorylation site

- heme binding site

FIGURE 1 | A model of the secondary structure organizations of (A) oleosin, (B) caleosin, and (C) steroleosin on the surface of plant seed oil bodies. Predicted structures of the proline knot or proline knob motif are shown in all three proteins. The model is mainly based on information from Chen et al. (1999); Hanano et al. (2006); d'Andréa et al. (2007), and Tzen (2012). TAG, Triacylglycerol; PL, phospholipid.

to the hydrophobic segment that is presumably responsible for association with the $\mathrm{OB}$ phospholipid monolayer. The core structure of the sterol-binding dehydrogenase/reductase domain contains a conserved NADPH-binding subdomain, a NSYK conserved active site region and a divergent sterol-binding subdomain (Figure 1) (Lin et al., 2002; d’Andréa et al., 2007).

Cotranslational and posttranslational modifications of OB-associated proteins may elevate their structural stability and prevent ubiquitination and degradation of OBs. Mass spectrum analyses showed that the first methionine in the N-termini of nascent oleosin and caleosin isoforms from sesame seed OBs is removed and the following alanine is acetylated. N-terminalacetylation is catalyzed by several distinct N-terminal acetyltransferases (NATs) in eukaryotes-NatA-NatF. N-termini with small amino acid residues in the second position (such as Met Ser-, Met Ala-, like oleosin and caleosin, Met Thr-, Met Val-), are mostly processed by methionine aminopeptidase (MAP), and the resulting newly generated $\mathrm{N}$-termini may be acetylated by NatA (Arnesen, 2011; Ree et al., 2018 ). However, candidates for the proposed acetyltransferase activities that modify the N-termini of oleosins have yet not been reported. Additionally, deamidation of a glutamine residue is also found in the $\mathrm{N}$-terminus of oleosin. Deamidation of glutamine residues have been considered to be the most common post-translational modification occurring in living systems and to be nonenzymatic reactions ( $\mathrm{Li}$ et al., 2010). This posttranslational modification introduces more negative charges to the protein surface and may reinforce $\mathrm{OB}$ stability by preventing aggregation under physiological conditions. Amino acid sequence analysis shows that both steroleosin isoforms (Sop2 and Sop3) possess a free initial methionine residue at their $\mathrm{N}$-termini. They also possess an $\mathrm{N}$-terminal sequence responsible for endoplasmic reticulim (ER) targeting via the signal-recognition particle (SRP) dependent pathway which anchors to OBs. No ER targeting signal sequences are present in the N-termini of caleosin or oleosin isoforms. Because of this signal sequence, no posttranslational cleavage or modification occurs in the $\mathrm{N}$-termini of the mature steroleosins (Lin et al., 2005).

\section{OLEOSINS FUNCTION DURING SEED MATURATION AND GERMINATION}

Oleosins are only found in plants, including green algae (Huang, 2013). However, in mammals and insects, a different set of abundant OB proteins, such as perilipins (PLINs) (Sztalryd and Kimmel, 2014) that are absent in plants, serve similar functions. Although the lipid bodies in yeast, such as Saccharomyces 
cerevisiae, are functionally similar to OBs in plant seeds, no oleosin homologs are present (Jacquier et al., 2013).

Oleosins have a variety of confirmed functions. They contribute to the stability and resolubility of OBs during seed (and pollen grain) desiccation, regulate $\mathrm{OB}$ size and viability in overwintering seeds, and are important for lipid mobilization during seed germination (Figure 2) (Schmidt and Herman, 2008; Shimada et al., 2008; Wu et al., 2010; Miquel et al., 2014).

\section{Oleosins Affect the Stability and Size of OBs}

Oleosins stabilize OBs by creating a negative charge on the $\mathrm{OB}$ surface which prevents $\mathrm{OB}$ coalescence due to steric hindrance and electrical repulsion (Tzen and Huang, 1992). $\mathrm{OB}$ reconstitution showed that oleosins are essential to avoid coalescence and important for maintaining the physical stability of OBs (Deleu et al., 2010). Oleosin concentrations have been reported to correlate with $\mathrm{OB}$ size in several oil plants including rape, mustard, cotton, flax, maize, peanut, sesame, olive, and avocado (Tzen et al., 1993; Ting et al., 1996). The size of OBs is inversely proportional to the concentration of oleosin: highoil seeds of maize with relatively low oleosin levels have large OBs, while low-oil seeds of maize with high oleosin levels have small OBs (Ting et al., 1996). Similarly, the avocado mesocarp cell, which does not express oleosin, has only one very large OB $(20 \mu \mathrm{m}$ in diameter) (Platt-Aloia and Thompson, 1981). Several studies in Arabidopsis and rice have shown that oleosin depletion caused by RNA interference (RNAi) leads to the appearance of unusually large and structurally abnormal OBs (Siloto et al., 2006; Miquel et al., 2014).

In mature Arabidopsis seeds, OLE1 and OLE2 accumulate at higher levels than OLE3 and OLE4, whereas OLE5 has the lowest abundance (Siloto et al., 2006; Miquel et al., 2014). Shimada et al. investigated the physiological function of oleosins using an oleosin-deficient mutant series of $A$. thaliana and found that oleosin levels affected germination and the freezing tolerance of seeds. Among the mutants used, the double Arabidopsis mutant ole1 ole2 has the lowest levels of oleosins and hardly germinates under normal conditions. In addition, freezing treatment followed by imbibition at $4^{\circ} \mathrm{C}$ accelerates the fusion of OBs and generates acentric nuclei (irregularly shaped nuclei found on the periphery of seed cells) leading to seed mortality and inhibition of seed germination in the ole 1 ole 2 mutant. Thus, oleosins increase seed viability and maintain seed germination by preventing abnormal fusion of OBs during overwintering (Shimada et al., 2008).

\section{Oleosins Regulate Lipid Metabolization}

Oleosins play an important role in regulating the biosynthesis, metabolization, and mobilization of lipids during seed maturation and germination (Parthibane et al., 2012). Increasing evidence suggests oleosins affect the lipid levels of plant organs. In S. cerevisiae, phosphatidic acid phosphohydrolase (PAH1) catalyzes the rate-limiting step for TAG formation, the

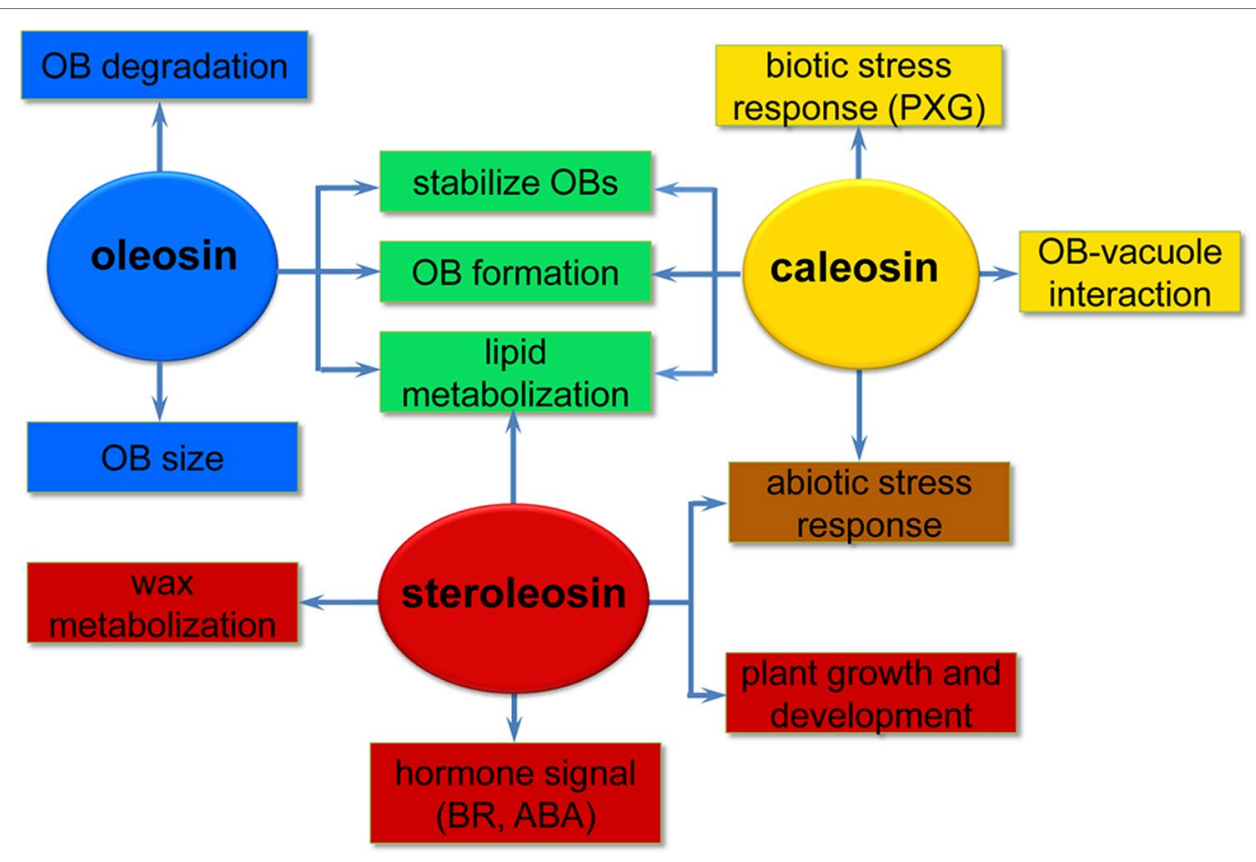

FIGURE 2 | A simplified overview of the putative roles of the three oil body (OB) intrinsic proteins in various processes of plant development. Oleosins (blue) mainly act as structural proteins stabilizing OBs and are involved in lipid metabolization during seed germination and seedling growth. Caleosins (orange) play important roles in biotic and abiotic stress responses through their peroxygenase (PXG) activities. Steroleosins (red) are involved in regulating plant growth and development mainly via an unknown mechanism by which the proteins interact with hormones such as brassinosteroids (BRs) and abcisic acid (ABA). Green indicates processes that both oleosin and caleosin are involved in. Brown indicates processes that both caleosin and steroleosin are involved with. 
dephosphorylation of phosphatidic acid to diacylglycerol (DAG), which play a direct role in OB biogenesis (Skinner et al., 2009). OB numbers of yeast cells lacking PAH1 (pah1 mutant) reduce by more than $60 \%$. PAH1, probably working through DAG, controls the formation of OBs (Adeyo et al., 2011). Ectopic expression of A. thaliana oleosin1 (OLE1) in pah1 cells not only increases the levels of newly synthesized neutral lipids including TAG and steryl esters (STE), but also increases OB formation. OBs are formed from membranes enriched in neutral lipids by promoting the sequestration of neutral lipids within the ER bilayer and protecting the TAG pool from hydrolysis by lipases (Jacquier et al., 2013). It is well known that diacylglycerol $O$-acyltransferase (DGAT1) is a critical enzyme involved in TAG synthesis via the acyl-CoA-dependent pathway in developing seeds (Chapman and Ohlrogge, 2012). Winichayakul et al. coexpressed Arabidopsis DGAT1 and a synthetically stabilized oleosin (cysteine [Cys]oleosin) from sesame seeds in Arabidopsis and S. cerevisiae. Both transgenic plants and yeast cells produced significantly increased neutral lipid levels in vegetative organs and yeast cells than in the respective wild type cells or when expressing DGAT1 alone. The increasing neutral lipids then elevates $\mathrm{CO}_{2}$ levels in the chloroplast, leading to a higher $\mathrm{CO}_{2}$ fixation rate and an increase in biomass production (Winichayakul et al., 2013). Overexpression of Arabidopsis seed OLE1 induces elevated leaf TAG levels in transgenic Arabidopsis plants. TAG content is increased up to sevenfold compared to wild type (Fan et al., 2013). Vanhercke et al. also obtained the similar results. They found that simultaneous expression in tobacco of the A. thaliana transcription factor WRI1, DGAT, and the S. indicum OLEOSIN gene caused TAG levels in tobacco leaves to dramatically increase (more than $15 \%$ of the dry weight) without a detrimental effect on plant development or seed viability (Vanhercke et al., 2014). Four Brassica napus oleosin genes were overexpressed in Arabidopsis increased the linoleic acid content (13.3\% at most) and the seed weight. In the meanwhile, the eicosaenoic acid content decreased by $11 \%$ in seeds of transgenic lines (Chen et al., 2019). The experimental evidence confirmed that oleosins play important roles in regulating lipid metabolization.

\section{Oleosins Play an Important Role in OB Formation and Degradation}

In seeds, oleosins are also involved in $\mathrm{OB}$ formation and degradation (Schmidt and Herman, 2008; Quettier and Eastmond, 2009). During OB biogenesis, oleosin is first integrated into the ER membrane before it is targeted to the OBs (Ting et al., 1997; Jacquier et al., 2013).

OBs are structurally and functionally conserved across species. Several studies demonstrated that plant oleosins from maize (Zea mays L.), sunflower, and B. napus are correctly targeted to endogenous OBs when heterologously expressed in S. cerevisiae or mammalian cells (Ting et al., 1997; Beaudoin et al., 2000; Hope et al., 2002). Thus, because of the convenience of using yeast cells, expression of plant oleosins in yeast cells is helpful to investigate the possible function of these proteins in neutral lipid homeostasis and $\mathrm{OB}$ biogenesis. In S. cerevisiae, four enzymes, including acyl-CoA: sterol acyltransferases (Are1 and
Are2) which produce STE, lecithin cholesterol acyltransferase (LCAT)-related protein (Lro1), and acyl-CoA: diacylglycerol acyltransferase (Dga1) which produces TAG, are involved in synthesis of neutral lipids and LD biogenesis (Oelkers et al., 2002; Czabany et al., 2007). In quadruple yeast mutant cells lacking OBs due to the deletion of all four genes, some OB-localized membrane proteins, such as Erg6 (an enzyme of the ergosterol biosynthetic pathway) or Dgal, are mislocalized in the ER bilayer. Induction of neutral lipid synthesis in these mutants leads to the formation of OBs and a concomitant relocalization of the mislocalized OB proteins from the ER onto OBs (Jacquier et al., 2011). Similarly, GFP-tagged versions of OLE1 from A. thaliana were expressed in $S$. cerevisiae and showed proper targeting of the protein to OBs. In wild-type yeast cells, GFP-OLE1 induces OB formation, but in yeast mutant cells lacking OBs GFP-OLE1 localizes to the ER membrane and is significantly less stable and rapidly degraded (Jacquier et al., 2013). These observations suggest that oleosins have high affinity for neutral lipids and phospholipids, probably due to the extraordinary architecture of oleosins which is ideal for localization within OBs.

During plant seed germination and seedling growth, oleosins are hydrolyzed by endogenous proteases as the initial step in lipase-induced TAGs mobilization. The hydrolysis of oleosins has been observed in many plant species. To date, the reported enzymes involved in this process include the ubiquitin/ proteasome system, the thioredoxin-regulated cysteine protease, and the aspartic protease, among others.

In plants, degradation of most intracellular proteins is via ubiquitination of the respective proteins and subsequent digestion by the proteasome (Sorokin et al, 2009). Ubiquitination of oleosins was first reported in young sesame seedlings. Ubiquitinated oleosin and caleosin were detected after seed imbibition by mass spectrometric analyses and further immunological detection using antibodies against ubiquitin (Hsiao and Tzen, 2011). Using proteomic and immunochemical approaches, Deruyffelaere et al. revealed the physiological regulation of oleosin ubiquitination during seed germination and defined the topologies of the ubiquitin attached to oleosins. OLE1-OLE5 are hydrolyzed sequentially by proteases just prior to lipid degradation in germinated seeds, concomitant with several posttranslational modifications of the oleosins. During this process, OLE5 degraded first, followed by OLE2 and OLE4, and then OLE1 and OLE3. The OLE5 and $8 \mathrm{kDa}$ proteolytic fragment of OLE2 are phosphorylated, while OLE1-OLE4 are ubiqutinated at the onset of lipid degradation. The ubiquitination topology of the oleosins is complex and differs for the various oleosins, suggesting distinct specific degradation pathways (Deruyffelaere et al., 2015). Recently, two research teams presented important insights into the mechanism regulating the extraction and turnover of oleosins in plants. Two key components, PUX10 (a member of the plant ubiquitin regulatory $\mathrm{X}$ (UBX)-domain containing protein family) and CDC48A (the AAA ATPase, Cell Division Cycle 48) were found. PUX10 localizes to OBs and binds to the ubiquitinated oleosins via its hydrophobic domain and interacts with ubiquitin and CDC48A via its UBA and UBX domains, respectively. As an adaptor, PUX10 recruits CDC48A to ubiquitinated oleosins, leading to dislocation of oleosins from 
OBs via the segregase activity of CDC48A (Deruyffelaere et al., 2018; Kretzschmar et al., 2018).

Trx $h$ (thioredoxin $h$ ) activates a thiol-protease to degrade the oleosin coat of OBs in sunflower (Helianthus annuus L.) seedlings (Babazadeh et al., 2012). In soybean, series analysis of proteases, including analyzing the specificity, optimal $\mathrm{pH}$, and temperature, suggest that $\mathrm{OB}$ extrinsic proteins, probably two thiol proteases of the papain family, Bd $30 \mathrm{~K}$ and P34, originated during seed maturation, are responsible for the hydrolysis of 24 and $18 \mathrm{kDa}$ oleosins (Chen et al., 2014). Similarly, a two-chain (32 and $9 \mathrm{kDa}$ ) aspartic protease was identified from the crude extract of peanut OBs. This enzyme shows high affinity for OBs and hydrolyzes both OB intrinsic proteins, such as oleosin, caleosin, steroleosin, and extrinsic proteins (Chen et al., 2018). However, these studies did not provide direct evidence for the interaction between endogenous proteases and oleosins, and the proteases for the oleosin hydrolysis were also not well-known.

Oleosins are involved in several OB functions. In addition to being the main structural protein to maintain OB stability, oleosins are important for the biogenesis and dynamics of the organelle. However, the precise mechanism underlying oleosins' functions, especially in $\mathrm{OB}$ degradation, and how oleosins interact with other proteins require further, more extensive research.

\section{CALEOSIN FUNCTIONS IN PLANT}

As the OB-associated proteins, besides being confined to the OB surface in plant seeds, caleosins have also been detected in vegetative tissues where they are associated with the endoplasmic reticulum, the vacuole and the envelope of chloroplasts (Hernandez-Pinzon et al., 2001; Carter et al., 2004; Partridge and Murphy, 2009). These diverse localizations suggest that distinct caleosins may fulfill various physiological functions in plant growth, development, and regulation of plant-environment interactions (Figure 2).

\section{Caleosins Affect the Stability of OBs and Lipid Metabolization}

Caleosins are also considered structural stabilizers of OBs. Analyses of lower plant species such as cycad (Cycas revoluta) confirm that OBs from megagametophytes are primarily associated with caleosin, while oleosin is absent (Jiang et al., 2009; Jiang and Tzen, 2010). In another case, stable artificial OBs composed of TAG and phospholipids can be stabilized by the addition of caleosin alone, in the absence of oleosin (Chen et al, 2004). Moreover, knockdown of a $24 \mathrm{kDa}$ oleosin using RNAi in soybean seed OBs is accompanied by an increased caleosin content, reflecting a compensatory mechanism of caleosin to maintain OB integrity (Schmidt and Herman, 2008).

Caleosin is involved in lipid metabolization and biogenesis of OBs. In Arabidopsis, AtCLO1 is exclusively expressed during seed development and its expression is not affected by exogenous abcisic acid (ABA) or osmotic stresses in vegetative tissues, indicating its seed-specific roles (Naested et al., 2000). Studies from two Arabidopsis Atclo1 mutants provide evidence for a role of caleosin in lipid degradation and trafficking in OBs during seed germination. Embryos from germinating Atclo1 mutant seeds exhibit a significant delay in the breakdown of storage lipid and display distorted vacuole morphology, abnormal internalization of vacuole membranes, and a significant decrease in OB-vacuole interactions. These results indicate that caleosin participates in the interactions between OBs and vacuoles that affect breakdown of OBs during germination (Poxleitner et al., 2006).

Heterologous AtCLO1 expression in yeast causes accumulation of $\mathrm{OB}$ neutral lipids, resulting in larger and more abundant OBs containing more fatty acids and steryl esters (Froissard et al., 2009). However, the impact of heterologous expression of caleosin versus oleosin in yeast is distinct, with oleosin expression inducing normal $\mathrm{OB}$ formation, and expressed oleosins were properly targeted to OBs (Ting et al., 1997; Jacquier et al., 2013). Thus, caleosin and oleosin play important but non-redundant roles in OB biogenesis.

\section{The Putative Role of Caleosins in Stress Responses}

The $\mathrm{Ca}^{2+}$-binding EF-hand motif in the N-terminus of caleosins is indicative of the protein's role in environmental adaptation. Calcium not only serves as a necessary nutrient for plant growth and development but also acts as one of the most important secondary messengers in many processes, such as cell division, apoptosis, polarity formation, photosynthesis, and stress resistance (Yang et al., 2017; Zheng et al., 2017; Jin et al., 2018). AtCLO3 [also designated RESPONSIVE TO DEHYDRATION20 (RD20)], a leaf caleosin isoform with $\mathrm{Ca}^{2+}$-dependent protein kinase activity, is strongly induced by many abiotic stresses such as drought, high salinity, and ABA, suggesting this protein may participate in stress signal transduction (Aubert et al, 2010; Aubert et al., 2011; Blée et al., 2014). Consistent with this idea, AtCLO3 knock-out plants show enhanced stomatal opening and reduced drought tolerance indicating that AtCLO3 plays an important role in the drought response by controlling stomatal aperture (Aubert et al., 2010). The expression of AtCLO4, another OB-associated caleosin in Arabidopsis, is down-regulated by exogenous ABA exposure and salt stress. The atclo4 mutant is hypersensitive to ABA during seed germination and shows increased drought tolerance in the adult stage. Exogenous ABA treatment in the atclo4 mutant leads to increased expression of some ABA-dependent regulatory genes, such as $A B F 3$ and $A B F 4$. Experimental data suggest that AtCLO4 functions as a negative regulator in ABA signaling and has important roles in the plant's response to environmental stresses, in addition to its possible roles in seed development and germination in Arabidopsis (Kim et al., 2011).

The presence of several heme-binding motifs in caleosin indicates that caleosins can bind heme and possess peroxygenase (PXG) functionality. In plant, peroxygenases catalyze hydroxylation and epoxidations of unsaturated fatty acids by transferring one oxygen atom from a hydroperoxide to the corresponding substrate, thus oxidizing it (Blée et al., 2012). Peroxygenase is also involved in the biosynthesis of plant oxylipins, a large family of oxidized fatty acids and 
metabolites originating from polyunsaturated fatty acids (PUFAs). Formation of oxylipins is mainly initiated by a-dioxygenases ( $\alpha$-DOX) or lipoxygenases (LOX) (Lòpez et al., 2011). a-DOX converts PUFAs into highly reactive 2-hydroperoxyoctadecatrienoic acids, which can be converted into the corresponding 2-hydroxyoctadecatrienoic acid or decomposed nonenzymatically into $\mathrm{CO}_{2}$ and shortened aldehyde derivatives (Hamberg et al., 2003). LOX catalyzes oxygenation of unsaturated fatty acids, yielding the corresponding fatty acid hydroperoxides, which are then reduced by peroxygenases into the corresponding fatty acid hydroxides (FAOH). Such oxylipins play significant roles in plant defense against pests and pathogens by inducing defense genes, regulating cell death or acting directly through their antimicrobial properties (Prost et al., 2005; Lòpez et al., 2011). Some caleosins, such as AtCLO1-4 from Arabidopsis, have been identified as calciumbinding heme-oxygenases with peroxygenase activity (Partridge and Murphy 2009; Kim et al., 2011).

Purified PXG (a caleosin from oat seed OBs) and crude extracts of yeast expressing the recombinant AtCLO1, AtCLO2, and EFA27 (a caleosin from rice) proteins were all able to perform co-oxidation reactions typical of peroxygenase, such as oxidizing thiobenzamide to its sulfoxide and oleic acid into 9,10-epoxystearate (Hanano et al., 2006).

In addition to induction by abiotic stresses, the expression of AtCLO3 is also enhanced by pathogens, suggesting a role in biotic stress responses as well (Shimada et al., 2014). The recombinant protein obtained from $S$. cerevisiae expressing the peroxygenase AtCLO3 was confirmed to possess hydroperoxide reductase activity, leading to the formation of endogenous $\mathrm{FAOH}$ from hydroperoxides of unsaturated fatty acids. Arabidopsis plants overexpressing AtCLO3 also accumulate 13-hydroxy-9,11,15octadecatrienoic acid, a linolenate-derived hydroxide. These FAOHs confer tolerance to oxidative stress by decreasing the accumulation of reactive oxygen species (ROS) and minimizing cell death (Blée et al., 2014). Microarray analysis in wild type plants showed that AtCLO3 is coexpressed with genes involved in the biosynthesis of very long chain fatty acids (VLCFA), components of seeds, and cuticular waxes. This experiment revealed that, compared to control plants, Arabidopsis overexpressing AtCLO3 exhibit an increased proportion of VLCFA in fatty acid composition of the seeds and contain higher amounts of alkanes and aldehydes in leaf cuticular waxes. As a result, altering the levels of these leaf cuticle wax components increases resistance to the fungus Alternaria brassicicola (Hanano et al., 2015). Shimada et al. observed that $\alpha$-DOX1 (a leaf OB protein with a-dioxygenase activity) and AtCLO3 work together to catalyze coupled reactions to produce 2-hydroxyoctadecanoic acid (2-HOT), which has antifungal activity against members of the genus Colletotrichum. Infection with C.higginsianum induces 2-HOT production and promotes formation of AtCLO3 and a-DOX1-positive OBs in the area around the site of infection. This study provides evidence of leaf $\mathrm{OB}$ function in plant defense via production of a phytoalexin under pathological conditions (Shimada et al., 2014; Shimada and Hara-Nishimura, 2015). Thus, the peroxygenase activities of these proteins were involved in the oxylipin signaling pathway and plant defense responses.
To date, among the Arabidopsis caleosin-like genes, possible roles have only been reported for AtCLO1, AtCLO3, and AtCLO4. The roles of the other caleosins remain largely uncharacterized.

\section{HSD EXPRESSION AND FUNCTION IN PLANT}

Compared with oleosin and caleosin proteins, HSDs are only minor components of OBs in oilseed plants and thus less emphasis has been placed on investigating steroleosins (d'Andréa et al., 2007). Unlike oleosin or caleosin, steroleosin does not play a key role in maintaining the structural stability and integrity of OBs. When stabilized only by recombinant steroleosin fusion proteins (F-steroleosin or DS steroleosin), artificial pine OBs lacking oleosin and caleosin are relatively unstable and larger than native OBs (Pasaribu et al., 2016). However, steroleosins play important roles in plant development and stress responses via the enzymatic activity of the HSDs and hormone signaling (Figure 2).

\section{Enzyme Activity and Substrate Analysis of HSDs}

OBs from different forms of life have been reported to possess HSD activity and to be involved in the metabolism of steroids. However, there have only been a few reports on the presence of active HSDs in plants. Studies suggest that Arabidopsis and $S$. indicum seed OBs contain $11 \beta$ - and $17 \beta$-HSD activities carried out by AtHSD1, and Sop2 and Sop3, respectively (Lin and Tzen, 2004; d’Andréa et al., 2007; Li et al., 2007).

Overexpressed Sop2 and Sop3 proteins are capable of oxidizing estradiol and corticosterone, thus exhibiting $17 \beta$ - and $11 \beta-H S D$ activities. However, they possess different sterol selectivities and $\mathrm{NADP}^{+}$specificities. Sop2 exhibits higher dehydrogenase activity to estradiol than to corticosterone in the presence of either $\mathrm{NADP}^{+}$or $\mathrm{NAD}^{+}$, and higher activity is detected using $\mathrm{NADP}^{+}$than $\mathrm{NAD}^{+}$as a cofactor when comparing the the same sterol substrate. In contrast, Sop3 is active and shows similar dehydrogenase activities to both examined sterols, but only in the presence of $\mathrm{NADP}^{+}$. Therefore, these two steroleosins may conduct different biological functions during the formation or degradation of seed OBs (Lin and Tzen, 2004).

Either within purified OBs from A. thaliana seeds or as a purified bacterially expressed chimeric enzyme in vitro, AtHSD1 is capable of catalyzing $\mathrm{NADP}^{+}$-dependent dehydrogenation of $11 \beta$ - and $17 \beta$-hydroxysteroids, including cortisol, corticosterone, and estradiol, indicating $11 \beta$ - and $17 \beta$ - HSD activity. Purified OBs also exhibit NADPH-dependent $17 \beta$-ketosteroid reductase activity by which estrone is converted into estradiol. $\mathrm{NADP}^{+}$, rather than $\mathrm{NAD}^{+}$, is the preferred cofactor for AtHSD1 (d'Andréa et al., 2007). OsHSD1 also displays $\mathrm{NADP}^{+}$and $\mathrm{NAD}^{+}$dependent dehydrogenase activity when using either estradiol or corticosterone as substrates, but shows higher dehydrogenase activity with $\mathrm{NAD}^{+}$than $\mathrm{NADP}^{+}$(Zhang et al., 2016). Steroleosin from $P$. massoniana OBs also exhibits sterol dehydrogenase activity with estradiol and corticosterone as substrates in the presence of $\mathrm{NADP}^{+}$(Pasaribu et al., 2016). 
AtHSD1 did not possess $3 \beta$-HSD activity as it cannot convert either cholesterol into 4-cholestene-3-one, or dehydroepiandrosterone (DHEA) into 4-androstene-3,17dione (4AD) under the experimental conditions. Thus, $3 \beta$-hydroxysterols are likely not substrates for AtHSD1, suggesting AtHSD1 might belong to the $17 \beta$-HSD superfamily (d'Andréa et al., 2007). 3 $\beta$-HSD activity of HSDs from other plants has also not yet been found.

\section{HSDs' Possible Role in Plant Growth and Development}

AtHSD1 expression is tissue specific and is strongly expressed in the above-ground parts of seedlings, especially vascular tissues, and is weakly expressed in root tissues. It has also been observed in the bud and silique pedicels (Li et al., 2007). AtHSD1 mRNA accumulation dramatically increases during seed and silique maturation, decreasing sharply during late maturation and the early germination process, resulting in full disappearance in fully germinated plantlets and in the vegetative organs and flowers of plants. AtHSD1 protein expression appears to be slightly delayed compared to mRNA accumulation as protein levels remain almost stable during the maturation phase and early germination (Baud et al., 2009). The 5' region of the AtHSD1 gene contains two RY motifs that are recognized by LEAFY COTYLEDON2 (LEC2) and FUSCA3 (FUS3) B3 domain proteins (Kroj et al., 2003; Braybrook et al., 2006). These proteins are transcriptional regulators that induce the expression of oleosin, caleosin and certain genes encoding key enzymes involved in fatty acid (FA) biosynthesis and oil accumulation in developing leaves and seeds (Guo et al., 2013; Tang et al., 2018). Therefore, AtHSD1 tissue specific expression seems to be controlled largely at the transcriptional level, with LEC2 being involved in the transcriptional activation of AtHSD1.

Both a loss-of-function hsd mutant produced by RNAi and transgenic Arabidopsis plants overexpressing AtHSD1 (AOHSD) have been used to analyze the function of AtHSD1. Compared to wild type plants, AOHSD plants show a series of phenotypes including reduced seed dormancy, thicker stems and increased growth, branching, flower production, and seed yield. Similarly, the increased growth phenotype found in AOHSD plants is also observed in transgenic B. napus plants overexpressing AtHSD1. Accordingly, the AtHSD1 RNAi mutant $(h s d)$ shows a semidwarfed phenotype. Together, the phenotypes of AOHSD plants and the hsd mutant demonstrate that AtHSD1 is involved in regulating growth and development in plants (Li et al., 2007).

The rice OsHSD1 protein is localized to both the ER and the OB surface and has a similar subcellular localization pattern as AtHSD1. It was found to be expressed in all organs tested including roots, culms, leaves, and panicles, with expression levels highest in leaf sheathes (Zhang et al., 2016). In the rice oshsd 1 mutant, in addition to a reduced plant height phenotype, a thin water film is formed on the leaf surface when the leaves are wetted due to a wax deficiency. Deletion of OsHSD1 is responsible for the wax-deficient phenotype, providing the first evidence that steroleosin is involved in wax metabolism. The cuticles on the surface of the mutant leaf show a reduced amount of epicuticular wax crystals and thicker cuticle membrane compared to wild type. Further analysis of the wax components showed that longchain fatty acids (C16 and C18) and VLCFAs (C26, C28, and C30), are significantly increased in the leaves of the mutant. This work provides new insights into HSDs involvement in wax and lipid metabolism.

\section{Response of AtHSD to BR, ABA, and Abiotic Stress}

Besides the phenotypes mentioned above, AOHSD plants also exhibit hypersensitivity to brassinosteroids (BRs), reduced sensitivity to ABA and increased catabolism of ABA (Li et al., 2007). In addition to these, observations also indicate that HSD may be involved in the stress response of plants.

As a powerful plant hormone, BR regulates some growth-specific processes including cell elongation, the promotion of seed germination and plant growth, vascular differentiation, ammonium uptake, photomorphogenesis, and skotomorphogenesis. BR-deficient mutants display extreme dwarf phenotypes (Noguchi et al., 1999). Experimental evidence confirmed that BR promotes seed germination by directly enhancing the growth potential of the emerging embryo (Leubner-Metzger, 2001). Interestingly, AtHSD1 expression is significantly induced by treatment with $\mathrm{BL}$ (brassinolide, the most active BR) in wild type plants but markedly decreased in BR-deficient mutants under similar treatment (Li et al., 2007). Additionally, the increased seed germination, growth and seed yield phenotypes of AOHSD plants are similar to those of plants that overproduce BRs (Choe et al., 2001), overexpress the BR receptor gene BRI1 (Nam and $\mathrm{Li}, 2002$ ) or of wild type plants treated with exogenous BL. AOHSD plants also show increased sensitivity to BRs. Accordingly, the AtHSD1 RNAi mutant ( $h s d$ ) is relatively insensitive to BRs. About 40 genes are significantly induced in AOHSD plants compared to wild type. The function of several these genes are similar to that of BL-induced genes encoding putative cell elongation or expansion-associated proteins, such as pectinesterase and xyloglucan fucosyltransferase (Li et al., 2007). The AOHSD phenotype appears to be due to enhancement of the effect of endogenous BRs or as a result of elevated BR concentrations; therefore, AtHSD is likely responsible for catalyzing a step in the biosynthesis of BRs or is involved in BR signaling (Li et al., 2007).

AtHSD1 gene expression affects sensitivity to and metabolism of ABA. ABA signaling plays an important role in many biological processes, such as embryo development, seed maturation, dormancy and germination, seedling establishment, vegetative development, root growth, stomatal movement, flowering, pathogen response, senescence, and stress response (Finkelstein, 2013; Wang et al., 2018). After ABA treatment, the levels of all ABA metabolites in AOHSD seeds are much higher than wild type. AOHSD seeds exhibit greatly reduced sensitivity to ABA, while $h s d$ mutant seeds are more sensitive to ABA during germination, similar to the BR biosynthetic mutant $\operatorname{det} 2-1$ and the BR-insensitive mutant bri1-1 (Steber and McCourt, 2001; Li et al., 2007).

Seed germination, plant growth and development are severely affected by various abiotic stresses (Ding et al., 
2018; He et al., 2018). Increasing evidence has accumulated demonstrating the interplay of HSDs and stress tolerance. For example, transgenic seeds of both Arabidopsis and canola which overexpress HSD (AOHSD and BOHSD) show increased salt tolerance compared to wild type (Li et al., 2007). The expression level of OsHSD1 is induced by $\mathrm{NaCl}$ and cold treatment, but is inhibited by drought treatment. Moreover, it is well known that the plant cuticular wax has many functions, including protection against UV radiation, resistance to pathogens and tolerance to environmental stresses (Bruhn et al., 2014; Sun et al., 2015). Studies have also provided some evidence for the relationship between abiotic stress and fatty acid metabolism (Thomas et al., 2012; Zhou et al., 2016; Wang et al., 2017; Sui et al., 2018). The role of OsHSD1 in wax and lipid metabolism and the fact that its expression is induced by $\mathrm{NaCl}$ and cold suggest OsHSD1 may be involved in environmental stress responses. However, the exact regulatory mechanism remains to be elucidated. The canola (B.napus) homolog of AtHSD1 also shows a putative role in stress response. The protein exhibits higher relative expression in imbibed seeds under polyethylene glycol (PEG) treatment than under treatment with the ABA analog PBI429, and also exhibits higher relative expression in nongerminating, $\mathrm{ABA}$ analog-treated seeds than in germinating seeds (Li et al., 2005).

Together, in A. thaliana, AtHSD1 has been reported to be important in regulating growth and development, stress tolerance, and produce BR-like effects. However, the genetic mechanisms of the effects and the role of AtHSD1 in response to BR action have not been established, and other HSD homologs have not yet been studied.

\section{INTERACTIONS BETWEEN OB-ASSOCIATED PROTEINS AND OTHER PROTEINS}

To properly understand the mechanisms of lipid storage regulation, it is essential to define the interactome of $\mathrm{OB}$-associated proteins. However, limited experimental evidence regarding the physical interactions of $\mathrm{OB}$-associated proteins has been obtained, primarily due to technical limitations, especially in plants (Tsai et al., 2015; Kolkhof et al., 2017).

Lipid droplet-associated proteins (LDAPs) are abundant components of OBs in non-seed cell types and are critical for the dynamic regulation of neutral lipid compartmentalization during various developmental and stress-related processes such as heat, cold, and drought conditions. LDAP3 is the most highly and ubiquitously expressed $L D A P$ gene in Arabidopsis, including in seeds (Gidda et al., 2016). Using the LDAP3 isoform as "bait" to screen a yeast two-hybrid library, Pyc et al. identified a new protein At5g16550, which they named LDIP (LDAP-interacting protein). The protein was confirmed to target specifically to the OB surface with further biochemical and cellular experiments. LDIP T-DNA mutants showed enlarged OBs and had increased total neutral lipid content in both leaves and seeds. These data suggest LDIP is a novel regulator in OB biology (Pyc et al., 2017).

Another case of protein-protein interaction during oleosin degradation in Arabidopsis germinated seeds has been mentioned above (Deruyffelaere et al., 2015). Ubiquitination of oleosins occurs at the onset of lipid degradation. Three distinct motifs, including monoubiquitin, K48-linked diubiquitin, and K63linked diubiquitin, are attached to the major oleosins OLE1 and OLE2. These distinct motifs designate oleosins toward different degradation pathways according to the ubiquitination type. Deruyffelaere et al. further confirmed that PUX10 localized to OBs interacts directly with ubiquitinated oleosins and mediates dislocation of oleosins by the AAA ATPase CDC48A (Deruyffelaere et al., 2018; Kretzschmar et al., 2018).

More work needs to be done to uncover the mechanism of interactions between $\mathrm{OB}$ associated proteins and other proteins in OB biology.

\section{OUTLOOK AND FUTURE PERSPECTIVES}

OB-associated proteins in seeds and the pollen of plants, mainly including oleosin, caleosin, and steroleosin, have been studied extensively in recent years. Although it has been gradually revealed that these proteins possess numerous functions important for cellular physiology, many questions remain.

Regarding $\mathrm{OB}$ biogenesis, the mechanisms regulating extraction of OBs to the cytosol and how OBs are recognized and bound by proteins remain incompletely understood. Postgerminative mobilization of neutral lipids stored in seed OBs is preceded by the degradation of OB-anchored proteins. However, the mechanisms underlying the dislocation of these proteins from the $\mathrm{OB}$ monolayer are still unknown. It has been known that these proteins are hydrolyzed by endogenous proteases during seed germination and seedling growth. But so far, little information concerning the identity of the endogenous protease has been revealed. In addition to oleosin, caleosin, and steroleosin, several other OB-associated proteins (such as OBAP1 identified in maize scutellum) have been detected recently (López-Ribera et al., 2014; Müller et al., 2017; Kretzschmar et al., 2018; De Chirico et al., 2018). Additionally, distinct populations of OBs have been found to exist in plants, each possessing different proteins, suggesting functional differentiation of OBs in plant seedlings. Further research is needed to study the mechanism of OB dynamics in other plant tissues and to determine what the roles of the newly identified OB-associated proteins in $\mathrm{OB}$ biogenesis and turnover may be.

Two OB-associated proteins, caleosin and steroleosin, were confirmed to participate in cellular stress defenses via enzymatic activities and hormone signaling, however, the genetic role of these genes in response to stress and hormone action has also not yet been established. For example, AOHSD plants exhibit hypersensitivity to $\mathrm{BR}$, insensitivity to $\mathrm{ABA}$ and increased stress tolerance. ABA and BRs have been shown to act antagonistically (Mandava, 1988); thus, it is difficult to reconcile how the BR-like effects of HSD can be associated with enhanced stress tolerance (which is promoted by ABA) (Li et al., 2007). Therefore, the relationship between $\mathrm{BR}, \mathrm{ABA}$, and stress tolerance may be more complex and further investigation will be required to define precise mode of action of HSDs in this process.

Moreover, several CLO genes or HSD genes are closely linked on the chromosomes in A. thaliana, so it is difficult to construct 
multiple mutants using traditional methods. This likely has limited research into caleosin and steroleosin. Now, the CRISPR system (Liang et al., 2018) and traditional crosses may be used to edit several genes simultaneously and construct multiple mutants in which all members of the CLO or HSD gene families could be knocked out, allowing for further functional analysis.

In short, continuing advances in analytic techniques and genomics will help to find more OB-associated proteins and further reveal the exact role of these proteins in stress response, lipid and BR metabolism, and OB formation. These studies may also provide novel opportunities for increasing stress resistance, enhancing plant yield or increasing the total TAG content in plant tissues for a variety of industrial applications.

\section{REFERENCES}

Adeyo, O., Horn, P. J., Lee, S., Binns, D. D., Chandrahas, A., Chapman, K. D., et al. (2011). The yeast lipin orthologue Pahlp is important for biogenesis of lipid droplets. J. Cell Biol. 192, 1043-1055. doi: 10.1083/jcb.201010111

Arnesen, T. (2011). Towards a functional understanding of protein $\mathrm{N}$ terminal acetylation. PloS Biol. 9, e1001074. doi: 10.1371/journal.pbio.1001074

Aubert, Y., Vile, D., Pervent, M., Aldon, D., Ranty, B., Simonneau, T., et al. (2010). RD20, a stress-inducible caleosin, participates in stomatal control, transpiration and drought tolerance in Arabidopsis thaliana. Plant Cell Physiol. 51, 1975-1987. doi: 10.1093/pcp/pcq155

Aubert, Y., Leba, L. J., Cheval, C., Ranty, B., Vavasseur, A., Aldon, D., et al. (2011). Involvement of RD20, a member of caleosin family, in ABA-mediated germination in Arabidopsis thaliana. Plant Signal. Behav. 6, 538-540. doi: 10.4161/psb.6.4.14836

Babazadeh, N., Poursaadat, M., Sadeghipour, H. R., and Colagar, A. H. Z. (2012). Oil body mobilization in sunflower seedlings is potentially regulated by thioredoxin h. Plant Physiol. Biochem. 57, 134-142. doi: 10.1016/j.plaphy.2012.05.013

Bao, B., Chao, H., Wang, H., Zhao, W., Zhang, L., Raboanatahiry, N., et al. (2018). Stable, environmental specific and novel QTL identification as well as genetic dissection of fatty acid metabolism in Brassica napus. Front. Plant Sci. 9, 1018. doi: $10.3389 /$ fpls.2018.01018

Baud, S., Dichow, N. R., Kelemen, Z., d’Andréa, S., To, A., Berger, N., et al. (2009). Regulation of HSD1 in seeds of Arabidopsis thaliana. Plant Cell Physiol. 50, 1463-1478. doi: 10.1093/pcp/pcp092

Beaudoin, F., Wikinson, B. M., Stirling, C. J., and Napier, A. (2000). In vivo targeting of a sunflower oil body protein in yeast secretory $(\mathrm{sec})$ mutants. Plant J. 23, 159-170. doi: 10. 1046/j.1365-313x.2000.00769.x

Blée, E., Flenet, M., Boachon, B., and Fauconnier, M. L. (2012). A non-canonical caleosin from Arabidopsis efficiently epoxidizes physiological unsaturated fatty acids with complete stereo selectivity. FEBS J. 279, 3981-3995. doi: 10.1111/j.1742-4658.2012.08757.x

Blée, E., Boachon, B., Burcklen, M., Le Guédard, M., Hanano, A., Heintz, D., et al. (2014). The reductase activity of the Arabidopsis caleosin RESPONSIVE TO DESSICATION 20 mediates gibberellin-dependent flowering time, abscisic acid sensitivity, and tolerance to oxidative stress. Plant Physiol. 166, 109-124. doi: 10.1104/pp.114. 245316

Braybrook, S. A., Stone, S. L., Park, S., Bui, A. Q., Le, B. H., Fischer, R. L., et al. (2006). Genes directly regulated by LEAFY COTYLEDON2 provide insight into the control of embryo maturation and somatic embryogenesis. Proc. Natl. Acad. Sci. U.S.A. 103, 3468-3473. doi: 10.1073/pnas.0511331103

Bruhn, D., Mikkelsen, T., Rolsted, M., Egsgaard, H., and Ambus, P. (2014). Leaf surface wax is a source of plant methane formation under UV radiation and in the presence of oxygen. Plant Biol. 16, 512-516. doi: 10.1111/plb.12137

Carter, C., Pan, S., Zouhar, J., Avila, E. L., Girke, T., and Raikhel, N. V. (2004). The vegetative vacuole proteome of Arabidopsis thaliana reveals predicted and unexpected proteins. Plant Cell 16, 3285-3303. doi: 10.1105/tpc.104.027078

Chapman, K. D., and Ohlrogge, J. B. (2012). Compartmentation of triacylglycerol accumulation in plants. J. Biol. Chem. 287, 2288-2294. doi: 10.1074/jbc. R111.290072

\section{AUTHOR CONTRIBUTIONS}

QS, PW, and CM conceived and wrote the manuscript. XL and TS contributed to the revision of the manuscript. All authors read and approved the submitted version.

\section{FUNDING}

This study was funded by the Key Technology Research and Development Program of Shandong (2018GSF121037 and 2018GNC113010) and the National Natural Science Foundation of China (31770290 and 31970301).

Chapman, K. D., Dyer, J. M., and Mullen, R. T. (2012). Biogenesis and functions of lipid droplets in plants. Thematic review series: lipid droplet synthesis and metabolism: from yeast to man. J. Lipid Res. 53, 215-226. doi: 10.1194/jlr.R021436

Charuchinda, P., Waditee-Sirisattha, R., Kageyama, H., Yamada, D., Sirisattha, S., Tanaka, Y., et al. (2015). Caleosin from Chlorella vulgaris TISTR 8580 is salt-induced and heme-containing protein. Biosci. Biotechnol. Biochem. 79, 1119-1124. doi: 10.1080/09168451.2015.1010480

Chen, E. C. F., Tai, S. S. K., Peng, C. C., and Tzen, J. T. C. (1998). Identification of three novel unique proteins in seed oil bodies of sesame. Plant Cell Physiol. 39, 935-941. doi: 10. 1093/oxfordjournals.pcp.a029457

Chen, C. F., Tsai, C. C. Y., and Tzen, J. T. C. (1999). Cloning and secondary structure analysis of caleosin, a unique calcium-binding protein in oilbodies of plant seeds. Plant Cell Physiol. 40, 1079-1086. doi: 10.1093/oxfordjournals. pcp.a029490

Chen, M. C., Chyan, C. L., Lee, T. T., Huang, S. H., and Tzen, J. T. (2004). Constitution of stable artificial oil bodies with triacylglycerol, phospholipid, and caleosin. J. Agric. Food Chem. 52, 3982-3987. doi: 10.1021/jf035533g

Chen, Y., Zhao, L., Cao, Y., Kong, X., and Hua, Y. (2014). Oleosins (24 and 18 kDa) are hydrolyzed not only in extracted soybean oil bodies but also in soybean germination. J. Agric. Food Chem. 62, 956-965. doi: 10.1021/jf405382w

Chen, Y., Chen, Y., Zhao, L., Kong, X., Yang, Z., and Hua, Y. (2018). A two-chain aspartic protease present in seeds with high affinity for peanut oil bodies. Food Chem., 241, 443-451. doi: 10.1016/j.foodchem.2017.09.020

Chen, K., Yin, Y., Liu, S., Guo, Z., Zhang, K., Liang, Y., et al. (2019). Genome-wide identification and functional analysis of oleosin genes in Brassica napus L. BMC Plant Biol. 19, 294. doi: 10.1186/s12870-019-1891-y

Choe, S., Fujioka, S., Noguchi, T., Takatsuto, S., Yoshida, S., and Feldmann, K. A. (2001). Overexpression of DWARF4 in the brassinosteroid biosyntheticpathway results in increased vegetative growth and seed yield in Arabidopsis. Plant J. 26, 573-582. doi: 10. 1046/j.1365-313x.2001.01055.x

Czabany, T., Athenstaedt, K., and Daum, G. (2007). Synthesis, storage and degradation of neutral lipids in yeast. Biochim. Biophys. Acta 1771, 299-309. doi: 10.1016/j.bbalip.2006.07.001

d’Andréa, M., Canonge, A., Beopoulos, P., Jolivet, M. A., Hartmann, M., Miquel, L. et al. (2007). At5g50600 encodes a member of the short-chain dehydrogenase reductase superfamily with $11 \beta$ - and $17 \beta$-hydroxysteroid dehydrogenase activities associated with Arabidopsis thaliana seed oil bodies. Biochimie 89, 222-229. doi: 10.1016/j.biochi.2006.09.013

D'Andrea, S. (2016). Lipid droplet mobilization: the different ways to loosen the purse strings. Biochimie 120, 17-27. doi: 10.1016/j.biochi.2015.07.010

De Chirico, S., di Bari, V., Foster, T., and Gray, D. (2018). Enhancing the recovery of oilseed rape seed oil bodies (oleosomes) using bicarbonatebased soaking and grinding media. Food Chem. 241, 419-426. doi: 10.1016/j. foodchem.2017.09.008

de Oliveira, D. E., Franco, L. O., Simoens, C., Seurinck, J., Coppieters, J., Botterman, J., et al. (1993). Inflorescence-specific genes from Arabidopsis thaliana encoding glycine-rich proteins. Plant J. 3, 495-507. doi: 10.1046/j.1365-313x.1993.03040495.x

Deleu, M., Vaca-Medina, G., Fabre, J., Roiz, J., Valentin, R., and Mouloungui, Z. (2010). Interfacial properties of oleosins and phospholipids from rapeseed for 
the stability of oil bodies in aqueous medium. Colloids Surf. B Biointerfaces 80, 125-132. doi: 10.1016/j. colsurfb.2010.05.036

Deruyffelaere, C., Bouchez, I., Morin, H., Guillot, A., Miquel, M., Froissard, M., et al. (2015). Ubiquitin-mediated proteasomal degradation of oleosins is involved in oil body mobilization during post-germinative seedling growth in Arabidopsis. Plant Cell Physiol. 56, 1374-1387. doi: 10.1093/pcp/pcv 056

Deruyffelaere, C., Purkrtova, Z., Bouchez, I., Collet, B., Cacas, J. L., Chardot, T., et al. (2018). PUX10 is a CDC48A adaptor protein that regulates the extraction of ubiquitinated oleosins from seed lipid droplets in Arabidopsis. Plant Cell 30, 2116-2136. doi: 10.1105/tpc.18. 00275

Ding, T. L., Yang, Z., Wei, X. C., Yuan, F., Yin, S. S., and Wang, B. S. (2018). Evaluation of salt-tolerant germplasm and screening of the salt-tolerance traits of sweet sorghum in the germination stage. Funct. Plant Biol. 45, 1073-1081. doi: 10.1071/FP18009

Fan, J., Yan, C., Zhang, X., and Xu, C. (2013). Dual role for phospholipid: diacylglycerol acyltransferase: enhancing fatty acid synthesis and diverting fatty acids from membrane lipids to triacylglycerol in Arabidopsis leaves. Plant Cell 253506, -3518. doi: 10.1104/pp.113.216820

Finkelstein, R. (2013). Abscisic acid synthesis and response. Arabidopsis Book 11, e0166. doi: 10.1199/tab.0166

Froissard, M., D’andréa, S., Boulard, C., and Chardot, T. (2009). Heterologous expression of AtClo1, a plant oil body protein, induces lipid accumulation in yeast. FEMS Yeast Res. 9, 428-438. doi: 10.1111/j.1567-1364.2009.00483.x

Gidda, S. K., Park, S., Pyc, M., Yurchenko, O., Cai, Y., Wu, P., et al. (2016). Lipid droplet-associated proteins (LDAPs) are required for the dynamic regulation of neutral lipid compartmentation in plant cells. Plant Physiol. 170, 2052-2071. doi: 10.1104/pp.15.01977

Guo, F. D., Liu, C. L., Xia, H., Bi, Y. P., Zhao, C. Z., Zhao, S. Z., et al. (2013). Induced expression of AtLEC1 and AtLEC2 differentially promotes somatic embryogenesis in transgenic tobacco plants. PloS One 8, e71714. doi: 10.1371/ journal.pone.0071714

Hamberg, M., Sanz, A., Rodriguez, M. J., Calvo, A. P., and Castresana, C. (2003). Activation of the fatty acid alpha-dioxygenase pathway during bacterial infection of tobacco leaves: formation of oxylipins protecting against cell death. J. Biol. Chem. 278, 51796-51805. doi: 10.1074/jbc.M310514200

Hanano, A., Burcklen, M., Flenet, M., Ivancich, A., Louwagie, M., Garin, J., et al. (2006). Plant seed peroxygenase is an original heme-oxygenase with an EF-hand calcium binding motif. J. Biol. Chem. 281, 33140-33151. doi: 10.1074/ jbc.M605395200

Hanano, A., Bessoule, J. J., Heitz, T., and Blée, E. (2015). Involvement of the caleosin/peroxygenase RD20 in the control of cell death during Arabidopsis responses to pathogens. Plant Signal. Behav. 10, e991574. doi: 10.4161/ 15592324.2014. 991574

He, M., He, C. Q., and Ding, N. Z. (2018). Abiotic stresses: general defenses of land plants and chances for engineering multistress tolerance. Front. Plant Sci. 9, 1771. doi: 10.3389/fpls.2018.01771

Hernandez-Pinzon, I., Patel, K., and Murphy, D. J. (2001). The Brassica napus calcium-binding protein caleosin has distinct endoplasmic reticulumand lipid body-associated isoforms. Plant Physiol. Biochem. 39, 615-622. doi: 10.1016/ S0981-9428(01)01274-8

Hope, R. G., Murphy, D. J., and McLauchlan, J. (2002). The domains required to direct core proteins of hepatitis C virus and GB virus-B to lipid droplets share common features with plant oleosin proteins. J. Biol. Chem. 277, 4261-4270. doi: 10.1074/jbc.M108798200

Hsiao, E. S., and Tzen, J. T. (2011). Ubiquitination of oleosin-H and caleosin in sesame oil bodies after seed germination. Plant Physiol. Biochem. 49, 77-81. doi: 10.1016/j.plaphy.2010.10.001

Huang, C. Y., and Huang, ,. A. H. C. (2017). Unique motifs and length of hairpin in oleosin target the cytosolic side of endoplasmic reticulum and budding lipid droplet. Plant Physiol. 174, 2248-2260. doi: 10.1104/pp.17.00366

Huang, C. Y., Chung, C. I., Lin, Y. C., Hsing, Y. C., and Huang, A. H. C. (2009). Oil bodies and oleosins in Physcomitrella possess characteristics representative of early trends in evolution. Plant Physiol. 150, 1192-1203. doi: 10.1104/ pp. 109.138123

Huang, A. H. C. (1996). Oleosin and oil bodies in seeds and other organs. Plant Physiol. 110, 1055-1061. doi: 10.1104/pp.110.4.1055

Huang, C. Y. (2013). Evolution and functions of oleosins and oleosin-coated oil bodies in plants (Riverside Press: University of California).
Jacquier, N., Choudhary, V., Mari, M., Toulmay, A., Reggiori, F., and Schneiter, R. (2011). Lipid droplets are functionally connected to the endoplasmic reticulum in Saccharomyces cerevisiae. J. Cell Sci. 124, 2424-2437. doi: 10.1242/jcs.076836

Jacquier, N., Mishra, S., Choudhary, V., and Schneiter, R. (2013). Expression of oleosin and perilipins in yeast promotes formation of lipid droplets from the endoplasmic reticulum. J. Cell. Sci. 126, 5198-5209. doi: 10.1242/jcs.131896

Jiang, P. L., and Tzen, J. (2010). Caleosin serves as the major structural protein as efficient as oleosin on the surface of seed oil bodies. Plant Signal. Behav. 5, 447-449. doi: 10.4161/psb. 5.4.10874

Jiang, P. L., Chen, J. C., Chiu, S. T., and Tzen, J. T. (2009). Stable oil bodies sheltered by a unique caleosin in cycad megagametophytes. Plant Physiol. Biochem. 471009-, 1016. doi: 10.1016/j.plaphy.2009.07.004

Jin, W. W., Long, Y., Fu, C. H., Zhang, L. B., Xiang, Wang, J., et al. (2018). $\mathrm{Ca}^{2+}$ imaging and gene expression profiling of Lonicera Confusa in response to calcium-rich environment. Sci. Rep. 8, 10. doi: 10.1038/s41598-018-25611-5

Jolivet, P., Roux, E., D’Andréa, S., Davanture, M., Negroni, L., Zivy, M., et al. (2004). Protein composition of oil bodies in Arabidopsis thaliana ecotype WS. Plant Physiol. Biochem. 42, 501-509. doi: 10.1016/j.plaphy.2004.04.006

Jolivet, P., Boulard, C., Bellamy, A., Larré, C., Barre, M., Rogniaux, H., et al. (2009). Protein composition of oil bodies from mature Brassica napus seeds. Proteomics 9, 3268-3284. doi: 10.1002/pmic.200800449

Kim, H. U., Hsieh, K., Ratnayake, C., and Huang, A. H. C. (2002). A novel group of oleosins is present inside the pollen of Arabidopsis. J. Biol. Chem. 27722677-, 22684. doi: 10.1074/jbc.M109298200

Kim, Y. Y., Jung, K. W., Yoo, K. S., Jeung, J. U., and Shin, J. S. (2011). A stressresponsive caleosin-like protein, AtCLO4, acts as a negative regulator of $\mathrm{ABA}$ responses in Arabidopsis. Plant Cell Physiol. 52, 874-884. doi: 10.1093/pcp/ pcr039

Kirik, V., Kolle, K., Balzr, H., and Baumlein, H. (1996). Two new oleosin isoforms with altered expression patterns in seeds of the Arabidopsis mutant fus3. Plant Mol. Biol. 31, 413-417. doi: 10.1007/bf00021803

Kolkhof, P., Werthebach, M., van de Venn, A., Poschmann, G., Chen, L., Welte, M., et al. (2017). A luciferase-fragment complementation assay to detect lipid droplet-associated protein-protein interactions. Mol. Cell Proteomics 16, 329345. doi: 10.1074/mcp.M116.061499

Kretzschmar, F. K., Mengel, L. F., Müller, A., Schmitt, K., Blersch, K. F., Valerius, O., et al. (2018). PUX10 is a lipid droplet-localized scaffold protein that interacts with CELL DIVISION CYCLE48 and is involved in the degradation of lipid droplet proteins. Plant Cell 30, 2137-2160. doi: 10.1105/tpc.18.00276

Kroj, T., Savino, G., Valon, C., Giraudat, J., and Parcy, F. (2003). Regulation of storage protein gene expression in Arabidopsis. Development 130, 6065-6073. doi: $10.1242 /$ dev.00814

López-Ribera, I., Paz, J. L. L., Repiso, C., García, N., Miquel, M., Hernández, M. L., et al. (2014). The evolutionary conserved oil body associated protein OBAP1 participates in the regulation of oil body size. Plant Physiol. 164, 1237-1249. doi: $10.1104 /$ pp.113.233221

Lòpez, M. A., Vicente, J., Kulaserakan, S., Vellosillo, T., Martinez, M., Irigoyen, M. I., et al. (2011). Antagonistic role of 9-lipoxygenase-derived oxylipins and ethylene in the control of oxidative stress, lipid peroxidation and plant defence. Plant J. 67, 447-458. doi: 10.1111/j.1365-313X.2011.04608.x

Leber, R., Zinser, E., Paltauf, F., Daum, G., and Zellnig, G. (1994). Characterization of lipid particles of the yeast, Saccharomyces cerevisiae. Yeast 10, 1421-1428. doi: 10.1002/yea.320101105

Leprince, O., van Aelst, A. C., Pritchard, H. W., and Murphy, D. J. (1998). Oleosins prevent oil-body coalescence during seed imbibition as suggested by a lowtemperature scanning electron microscope study of desiccation-tolerant and -sensitive oilseeds. Planta 204, 109-119. doi: 10.1007/s004250050236

Leubner-Metzger, G. (2001). Brassinosteroids and gibberellins promote tobacco seed germination by distinct pathways. Planta. 213, 758-763. doi: 10.1007/ s004250100542

Li, F., Wu, X. Z., Tsang, E., and Cutler, A. J. (2005). Transcriptional profiling of imbibed Brassica napus seed. Genomics. 86, 718-730. doi: 10.1016/j.ygeno.2005.07.006

Li, F., Asami, T., Wu, X., Tsang, E. W., and Cutler, A. J. (2007). A putative hydroxysteroid dehydrogenase involved in regulating plant growth and development. Plant Physiol. 145, 87-97. doi: 10.1104/pp.107.100560

Li, X., Lin, C., and O'Connor, P. B. (2010). Glutamine deamidation: differentiation of glutamic acid and gamma-glutamic acid in peptides by electron capture dissociation. Anal. Chem. 82, 3606-3615. doi: 10.1021/ac9028467 
Liang, Z., Chen, K., Yan, Y., Zhang, Y., and Gao, C. (2018). Genotyping genomeedited mutations in plants using CRISPR ribonucleoprotein complexes. Plant Biotechnol. J. 12, 2053-2062. doi: 10.1111/pbi.12938

Lin, L. J., and Tzen, J. T. C. (2004). Two distinct steroleosins are present in seed oil bodies. Plant Physiol. Biochem. 42, 601-608. doi: 10.1016/j.plaphy.2004.06.006

Lin, L. J., Tai, S. S., Peng, C. C., and Tzen, J. T. (2002). Steroleosin, a sterol-binding dehydrogenase in seed oil bodies. Plant Physiol. 128, 1200-1211. doi: 10.1104/ pp.010928

Lin, L. J., Liao, P. C., Yang, H. H., and Tzen, J. T. (2005). Determination and analyses of the N-termini of oil-body proteins, steroleosin, caleosin and oleosin. Plant Physiol. Biochem., 43, 770-776. doi: 10.1016/j.plaphy.2005.07.008

Müller, A. O., Blersch, K. F., Gippert, A. L., and Ischebeck, T. (2017). Tobacco pollen tubes -a fast and easy tool for studying lipid droplet association of plant proteins. Plant J. 89, 1055-1064. doi: 10.1111/tpj.13441

Mandava, N. B. (1988). Plant growth-promoting brassinosteroids. Annu. Rev. Plant Physiol. Plant Mol. Biol. 39, 23-52. doi: 10.1146/annurev.pp.39.060188.000323

Mayfield, J. A., and Preuss, D. (2000). Rapid initiation of Arabidopsis pollination requires the oleosin-domain protein GRP17. Nat. Cell Biol. 2, 128-130. doi: $10.1038 / 35000084$

Mayfield, J. A., Fiebig, A., Johnstone, S. E., and Preuss, D. (2001). Gene families from the Arabidopsis thaliana pollen coat proteome. Science 292, 2482-2485. doi: $10.1126 /$ science. 1060972

Miquel, M., Trigui, G., d’Andréa, S., Kelemen, Z., Baud, S., Berger, A., et al. (2014). Specialization of oleosins in oil body dynamics during seed development in Arabidopsis seeds. Plant Physiol. 164, 1866-1878. doi: 10.1104/pp.113.233262

Murphy, D. J. (2001). The biogenesis and functions of lipid bodies in animals, plants and microorganisms. Prog. Lipid Res. 40, 325-438. doi: 10.1016/ S0163- 7827(01)00013-3

Naested, H., Frandsen, G. I., Jauh, G. Y., Hernandez-Pinzon, I., Nielsen, H. B., Murphy, D. J., et al. (2000). Caleosins: $\mathrm{Ca}^{2+}$-binding proteins associated with lipid bodies. Plant Mol. Biol. 44, 463-476. doi: 10.1023/A:1026564411918

Nam, K. H., and Li, J. (2002). BRI1/BAK1, a receptor kinase pair mediating brassinosteroid singaling. Cell 110, 203-212. doi: 10.1016/ s0092-8674(02)00814- 0

Noguchi, T., Fujioka, S., Choe, S., Takatsuto, S., Yoshida, S., Yuan, H., et al. (1999). Brassinosteroid-insensitive dwarf mutants of Arabidopsis accumulate brassinosteroids. Plant Physiol. 121, 743-752. doi: 10.1104/pp.121.3.743

Oelkers, P., Cromley, D., Padamsee, M., Billheimer, J. T., and Sturley, S. L. (2002). The DGA1 gene determines a second triglyceride synthetic pathway in yeast. J. Biol. Chem. 277, 8877-8881. doi: 10.1074/jbc.M111646200

Parthibane, V., Rajakumari, S., Venkateshwari, V., Iyappan, R., and Rajasekharan, R. (2012). Oleosin is bifunctional enzyme that has both monoacylglycerol acyltransferase and phospholipase activities. J. Biol. Chem. 287, 1946-1954. doi: 10.1074/jbc.M111.309955

Partridge, M., and Murphy, D. J. (2009). Roles of a membrane-bound caleosin and putative peroxygenase in biotic and abiotic stress responses in Arabidopsis. Plant Physiol. Biochem. 47, 796-806. doi: 10.1016/j.plaphy.2009.04.005

Pasaribu, B., Chung, T. Y., Chen, C. S., Jiang, P. L., and Tzen, J. T. C. (2016). Identification of steroleosin in oil bodies of pine megagametophytes. Plant Physiol. Biochem. 101, 173-181. doi: 10.1016/j.plaphy.2016.02.008

Platt-Aloia, K. A., and Thompson, W. W. (1981). Ultrastructure of the mesocarp of mature avocado fruit and changes associated with ripening. Ann. Bot. 48, 451-465. doi: 10.1093/oxfordjournals.aob.a086149

Poxleitner, M., Rogers, S. W., Lacey Samuels, ,. A., Browse, J., and Rogers, J. C. (2006). A role for caleosin in degradation of oil-body storage lipid during seed germination. Plant J. 47, 917-933. doi: 10.1111/j.1365-313X.2006.02845.x

Prost, I., Dhondt, S., Rothe, G., Vicente, J., Rodriguez, M. J., Kift, N., et al. (2005). Evaluation of the antimicrobial activities of plant oxylipins support their involvement in defense against pathogens. Plant Physiol. 139, 1902-1913. doi: 10.1104/pp.105.066274

Pyc, M., Cai, Y., Greer, M. S., Yurchenko, O., Chapman, K. D., Dyer, J. M., et al. (2017). Turning over a new leaf in lipid droplet biology. Trends Plant Sci. 22, 596-609. doi: 10.1016/j.tplants.2017.03.012

Quettier, A. L., and Eastmond, P. J. (2009). Storage oil hydrolysis during early seedling growth. Plant Physiol. Biochem. 47, 485-490. doi: 10.1016/j. plaphy.2008.12.005

Ree, R., Varland, S., and Arnesen, T. (2018). Spotlight on protein N-terminal acetylation. Exp. Mol. Med. 50, 90. doi: 10.1038/s12276-018-0116-Z
Schmidt, M. A., and Herman, E. M. (2008). Suppression of soybean oleosin produces micro-oil bodies that aggregate into oil body/ER complexes. Mol. Plant 1, 910-924. doi: 10.1093/mp/ssn049

Shen, Y., Xie, J., Liu, R. D., Ni, X. F., Wang, X. H., Li, Z. X., et al. (2014). Genomic analysis and expression investigation of caleosin gene family in Arabidopsis. Biochem. Biophys. Res. Commun. 448, 365-371. doi: 10.1016/j.bbrc

Shimada, T. L., and Hara-Nishimura, I. (2015). Leaf oil bodies are subcellular factories producing antifungal oxylipins. Curr. Opin. Plant Biol. 25, 145-150. doi: 10.1016/j.pbi.2015.05.019

Shimada, T. L., Shimada, H., Takahashi, H., and Fukao, Y. (2008). A novel role of oleosins in freezing tolerance of oilseeds in Arabidopsis thaliana. Plant J. 55, 798-809. doi: 10.1111/j.1365-313X.2008.03553.x

Shimada, T. L., Takano, Y., Shimada, T., Fujiwara., M., Fukao, Y., Mori, M., et al. (2014). Leaf oil body functions as a subcellular factory for the production of a phytoalexin in Arabidopsis. Plant Physiol. 164, 105-118. doi: 10.1104/ pp.113.230185

Shimada, T. L., Hayashi, M., and Hara-Nishimura, I. (2018). Membrane dynamics and multiple functions of oil bodies in seeds and leaves. Plant Physiol. 176, 199-207. doi: 10.1104/pp.17.01522

Siloto, R. M. P., Findlay, K., Lopez-Villabos, A., Yeung, E. C., Nykiforuk, C. L., and Moloney, M. M. (2006). The accumulation of oleosins determines the size of seed oil bodies in Arabidopsis. Plant Cell. 18, 1961-1974. doi: 10.1105/ tpc. 106.041269

Skinner, J. R., Shew, T. M., Schwartz, D. M., Tzekov, A., Lepus, C. M., Abumrad, N. A., et al. (2009). Diacylglycerol enrichment of endoplasmic reticulum or lipid droplets recruits perilipin 3/TIP47 during lipid storage and mobilization. J. Biol. Chem. 284, 30941-30948. doi: 10.1074/jbc.M109.013995

Song, Y. H., Wang, X. D., and Rose, R. J. (2017). Oil body biogenesis and biotechnology in legume seeds. Plant Cell Rep. 36, 1519-1532. doi: 10.1007/ s00299-017-2201-5

Sorokin, A. V., Kim, E. R., and Ovchinnikov, L. P. (2009). Proteasome system of protein degradation and processing. Biochem. (Mosc) 74, 1411-1442. doi: 10.1134/S000629790913001X

Steber, C. M., and McCourt, P. (2001). A role for brassinosteroids in germination in Arabidopsis. Plant Physiol. 125, 763-769. doi: 10.1104/pp.125.2.763

Sui, N., Wang, Y., Liu, S. S., Yang, Z., Wang, F., and Wan, S. B. (2018). Transcriptomic and physiological evidence for the relationship between unsaturated fatty acid and salt stress in peanut. Front. Plant Sci. 9, 7. doi: 10.3389/fpls.2018.00007

Sun, W., Li, Y., Zhao, Y. X., and Zhang, H. (2015). The TsnsLTP4, a nonspecific lipid transfer protein involved in wax deposition and stress tolerance. Plant Mol. Biol. Rep. 33, 962-974. doi: 10.1007/s11105-014-0798-x

Sztalryd, C., and Kimmel, A. R. (2014). Perilipins: lipid droplet coat proteins adapted for tissue-specific energy storage and utilization, and lipid cytoprotection. Biochimie 96, 96-101. doi: 10.1016/j.biochi.2013.08.026

Tang, G. Y., Xu, P. L., Ma, W. H., Wang, F., Liu, Z. J., Wan, S. B., et al. (2018). Seed-specific expression of AtLEC1 increased oil content and altered fatty acid composition in seeds of pPeanut (Arachis hypogaea L.). Front. Plant Sci. 9, 260. doi: 10.3389/fpls.2018.00260

Thomas, D., Patrick, G., Zuther, E., Bettina, S., Hincha, D. K., and Willmitzer, L. (2012). Differential remodeling of the lipidome during cold acclimation in natural accessions of Arabidopsis thaliana. Plant J. Cell. Mol. Biol. 72, 972-982. doi: $10.1111 /$ tpj. 12007

Ting, J. T., Lee, K., Ratnayake, C., Platt, K. A., Balsamo, R. A., and Huang, A. H. (1996). Oleosin genes in maize kernels having diverse oil contents are constitutively expressed independent of oil contents. Planta 199, 158-165. doi: $10.1007 /$ bf001968924

Ting, J. T. L., Balsamo, R. A., Ratnayake, C., and Huang, A. H. C. (1997). Oleosin of plant seed oil bodies is correctly targeted to the lipid bodies in transformed yeast. J. Biol. Chem. 272, 3699-3706. doi: 10.1074/jbc.272.6.3699

Tsai, C. H., Zienkiewicz, K., Amstutz, C. L., Brink, B. G., Warakanont, J., Roston, R., et al. (2015). Dynamics of protein and polar lipid recruitment during lipid droplet assembly in Chlamydomonas reinhardtii. Plant J. 83, 650-660. doi: $10.1111 /$ tpj.12917

Tzen, J. T. C., and Huang, A. H. C. (1992). Surface structure and properties of plant seed oil bodies. J. Cell Biol. 117, 327-335. doi: 10.1083/jcb.117.2.327

Tzen, J. T. C., Lai, Y. K., Chan, K. L., and Huang, A. H. C. (1990). Oleosin isoforms of high and low molecular weights are present in the oil bodies of diverse seed species. Plant Physiol. 94, 1282-1289. doi: 10.1104/pp.94.3.1282 
Tzen, J. T. C., Cao, Y. Z., Laurent, P., Ratnayake, C., and Huang, A. H. C. (1993). Lipids, proteins, and structure of seed oilbodies from diverse species. Plant Physiol. 101, 267-276. doi: 10.1104/pp.101.1.267

Tzen, J. T. C., Peng, C. C., Cheng, D. J., Chen, E. C. F., and Chiu, J. M. H. (1997). A new method for seed oil body purification and examination of oil body integrity following germination. J. Biochem. 121, 762-768. doi: 10.1093/ oxfordjournals.jbchem.a021651

Tzen, J. T. (2012). Integral proteins in plant oil bodies. ISRN Bot. 2012, 1-16. doi: $10.5402 / 2012 / 173954$

van Rooijen, G. J. H., Terning, L. I., and Moloney, M. M. (1992). Nucleotide sequence of an Arabidopsis thaliana oleosin gene. Plant Mol. Biol. 18, 11771179. doi: $10.1007 /$ bf00047721

Vance, V. B., and Huang, A. H. (1987). The major protein from lipid bodies of maize. Characterization and structure based on cDNA cloning. J. Biol. Chem. 262, 11275-11279.

Vanhercke, T., El Tahchy, A., Liu, Q., Zhou, X. R., Shrestha, P., Divi, U. K., et al. (2014). Metabolic engineering of biomass for high energy density: oilseed-like triacylglycerol yields from plant leaves. Plant Biotechnol. J. 12, 231-239. doi: $10.1111 / \mathrm{pbi} .12131$

Wältermann, M., Hinz, A., Robenek, H., Troyer, D., Reichelt, R., Malkus, U., et al. (2005). Mechanism of lipid-body formation in prokaryotes: how bacteria fatten up. Mol. Microbiol. 55, 750-763. doi: 10.1111/j.1365-2958.2004.04441.x

Wang, J. S., Zhang, Q., Cui, F., Hou, L., Zhao, S. Z., Xia, H., et al. (2017). Genome-wide analysis of gene expression provides new insights into cold responses in Thellungiella salsuginea. Front. Plant Sci. 8, 713. doi: 10.3389/ fpls.2017.00713

Wang, K., He, J. N., Zhao, Y., Wu, T., Zhou, X. F., Ding, Y. L., et al. (2018). EAR1 negatively regulates $\mathrm{ABA}$ signaling by enhancing $2 \mathrm{C}$ protein phosphatase activity. Plant Cell 30, 815-834. doi: 10.1105/tpc.17.00875

Winichayakul, S., Scott, R. W., Roldan, M., Hatier, J. H., Livingston, S., Cookson, R., et al. (2013). in Vivo Packaging of Triacylglycerols Enhances Arabidopsis Leaf Biomass and Energy Density. Plant Physiol. 162, 626-639. doi: 10.1104/ Pp.113.216820

Wu, Y. Y., Chou, Y. R., Wang, C. S., Tseng, T. H., Chen, L. J., and Tzen, J. T. (2010). Different effects on triacylglycerol packaging to oil bodies in transgenic rice seeds by specifically eliminating one of their two oleosin isoforms. Plant Physiol. Biochem. 48, 81-89. doi: 10.1016/j.plaphy.2009.12.004
Yang, S., Li, L., Zhang, J. L., Geng, Y., Guo, F., Wang, J. G., et al. (2017). Transcriptome and differential expression profiling analysis of the mechanism of $\mathrm{Ca}^{2+}$ regulation in peanut (Arachis hypogaea) pod development. Front. Plant Sci. 8, 1609. doi: 10.3389/fpls.2017.01609

Yin, Y. T., Guo, L. X., Chen, K., Guo, Z. Y., Chao, H. B., Wang, B. S., et al. (2018). 3D Reconstruction of lipid droplets in the seed of Brassica napus. Sci. Rep. 8, 6560. doi: 10.1038/s41598-018-24812-2

Zhang, S. O., Box, A. C., Xu, N., Le Men, J., Yu, J., Guo, F., et al. (2010). Genetic and dietary regulation of lipid droplet expansion in Caenorhabditis elegans. Proc. Natl. Acad. Sci. U.S.A. 107, 4640-4645. doi: 10.1073/pnas.09123081 07

Zhang, Z., Cheng, Z. J., Gan, L., Zhang, H., Wu, F. Q., Lin, Q. B., et al. (2016). OsHSD1, a hydroxysteroid dehydrogenase, is involved in cuticle formation and lipid homeostasis in rice. Plant Sci. 249, 35-45. doi: 10.1016/j. plantsci.2016.05.005

Zheng, Y., Liao, C., Zhao, S., Wang, C., and Guo, Y. (2017). The glycosyltransferase QUA1 regulates chloroplast-associated calcium signaling during salt and drought stress in Arabidopsis. Plant Cell Physiol. 58, 329-341. doi: 10.1093/pcp/ pcw192

Zhou, J. C., Fu, T. T., Sui, N., Guo, J. R., Feng, G., Fan, J. L., et al. (2016). The role of salinity in seed maturation of the euhalophyte Suaeda salsa. Plant Biosyst. 150, 83-90. doi: doi.10.1080/11263504.2014.976294

Zou, J. T., Abrams, G. D., Barton, D. L., Taylor, D. C., Pomeroy, M. K., and Abrams, S. R. (1995). Induction of lipid and oleosin biosynthesis by (+)- abscisic acid and its metabolites in microspore-derived embryos of Brassica napus L.cv reston (biological responses in the presence of 8 [prime]-hydroxyabscisic acid). Plant Physiol. 108, 563-571. doi: 10.1104/pp.108.2.563

Conflict of Interest: The authors declare that the research was conducted in the absence of any commercial or financial relationships that could be construed as a potential conflict of interest.

Copyright (C) 2019 Shao, Liu, Su, Ma and Wang. This is an open-access article distributed under the terms of the Creative Commons Attribution License (CC $B Y)$. The use, distribution or reproduction in other forums is permitted, provided the original author(s) and the copyright owner(s) are credited and that the original publication in this journal is cited, in accordance with accepted academic practice. No use, distribution or reproduction is permitted which does not comply with these terms. 